\title{
El pensamiento internacionalista en la era Lula
}

\author{
Raúl Bernal - Meza*
}

\section{INTRODUCCIÓN}

No hay dudas acerca del ascenso del Brasil en las estructuras de poder mundial. Actualmente el país integra el reducido grupo de países que pasaron de una inicial inserción periférica y subordinada en el siglo XIX a formar parte del segmento más dinámico de la semiperiferia ${ }^{1}$. En ese camino, en el

Profesor Titular de Relaciones Internacionales de la Universidad Nacional del Centro de la Provincia de Buenos Aires y profesor de la Universidad de Buenos Aires.

1 Utilizamos aquí la categoría formulada por Immanuel WALLERSTEIN (1979) y Giovanni Arrighi, que este último aplica a países como Brasil «que, a pesar de haber experimentado transformaciones sociales y económicas de largo alcance, frecuentemente asociadas a convulsiones políticas, en aspectos importantes no consiguieron alcanzar al selecto grupo de Estados que, en algún momento, establecieron los patrones de status y riqueza del sistema mundial» (Arrigui,1998:137-138). período 2003-2010, la política exterior, junto a la formulación de un nuevo regionalismo como estrategia de inserción global y un nuevo modelo ideal de Estado, ha sido un factor clave.

Como otros gobiernos, el presidente Lula da Silva formó parte de la renovación gubernamental de modelos económicos, políticas exteriores y de estrategias de inserción internacional que caracterizaron la transición de la mayoría de los países latinoamericanos entre el fin del siglo XX y principios del XXI. Los recambios de alianzas de gobierno y tendencias políticas fueron la respuesta de las sociedades nacionales a la crisis generada por el modelo neoliberal y la implementación de políticas públicas de acuerdo a una visión ideológica y fundamentalista de la globalización ${ }^{2}$, que incluyeron la transferencia de activos

2 Para una visión sobre esta interpretación de la «globalización», cfr. Ferrer (1998), Rapoport (1997) y Bernal-Meza (1996; 2000). 
nacionales (públicos y privados) al capital transnacional, la apertura unilateral de las economías, la desregulación de los mercados (financiero, comercial y laboral) y, en general, una política de sumisión y, en casos, de "servilismo", respecto de Estados Unidos y el capitalismo central. La diferencia con el resto de países es que Brasil cuenta con los atributos geográficos, económicos, demográficos y culturales para aplicarse a ese desafío de formar parte del grupo de actores centrales del sistema internacional contemporáneo.

Durante las administraciones de Lula da Silva la política exterior encontraría un rumbo definido, que la enlazaría con la etapa de reformulación y cambio que había caracterizado la década de 1970, durante la cual la gran política fue asociada a objetivos comerciales y económicos.

Después de un período de gran dinamismo en política exterior (apertura a África; participación activa en las agendas del mundo en desarrollo) y de un fuerte crecimiento económico, cambios internos y externos llevaron a una sensación de agotamiento de estas estrategias. El modelo de política exterior de la década de 1980, de las presidencias Figueiredo y Sarney, asociado al «desarrollo nacional», había evolucionado hacia una fase de crisis y contradicciones (Cervo y Bueno, 1992; Cervo, 1994). Es en este contexto que Collor de Mello lanza su plataforma de política exterior que modificaría el rumbo en tres aspectos: actualizar la agenda externa; construir una nueva agenda prioritaria y no conflictiva con Estados Unidos y reducir el perfil tercermundista (Hirst y Pinheiro,1995).

La crisis política interna - renuncia y destitución de Collor y su reemplazo por Itamar Franco- modificó sustancialmente las expectativas. Surgieron en ese contexto dos posiciones dentro de Itamaraty: una que veía el acercamiento a Estados Unidos como el camino para recuperar la «credibilidad internacional», siguiendo el modelo de política exterior del presidente argentino Carlos Menem, y otro que proponía la búsqueda de mayor autonomía y el distanciamiento de Washington, explotando también la condición de Brasil como potencia media ${ }^{3}$. Mientras la segunda comenzaría a advertirse con Itamar Franco, la primera caracterizaría a las dos administraciones de F.H. Cardoso.

La política exterior de Franco buscaría posicionar a su país en el liderazgo sudamericano del regionalismo, con su propuesta del Acuerdo de Libre Comercio Sudamericano (ALCSA), vis-à-vis los Estados Unidos y su proyecto de integración hemisférica fue seguido por la política exterior neo-idealista de las dos administraciones de F.H. Cardoso, política cercana al pensamiento dominante en el centro del capitalismo mundial y que sería marcada por los cuestionamientos y críticas (Cervo, 2002; 2008a; Bernal-Meza, 2002; 2009a).

Las interpretaciones de este concepto en la política exterior latinoamericana pueden verse en Bernal-Meza, R (2000:337-338); también en Bernal-Meza, R. (2005:225234) y del mismo autor en $\left(2009^{\mathrm{a}}\right)$. 
Raúl Bernal Meza • El pensamiento internacionalista...

El presidente Luiz Inácio Lula da Silva no solo representa un cambio significativo respecto del pensamiento en política internacional predominante en el período anterior (F.H. Cardoso), sino en el modelo ideal de Estado necesario para la inserción en el contexto sistémico marcado por la transición del orden y la globalización de la economía-mundo capitalista. Ambos aspectos marcarán lo que su gobierno haría respecto de la integración, la cooperación sudamericana y los sistemas político y económico mundiales.

Lula llega al gobierno brasileño al comenzar un nuevo siglo, en un sistema mundial caracterizado por dos procesos: uno en el ámbito del subsistema político, que corresponde a la transición hacia un nuevo orden que sustituirá al mundo bipolar y otro en la economía política, identificado con la globalización/mundialización ${ }^{4}$

$4 \quad$ Utilizamos el concepto de mundialización como categoría analítica para identificar el proceso económico global que da cuenta de las nuevas formas asumidas por la acumulación capitalista (producción, comercio, desarrollos científico-tecnológicos, inversiones) generados a partir de la crisis de los años setenta, caracterizada por la cartelización, la concentración oligopólica, la monopolización, etc.; con un predominio del capital financiero sobre el capital industrial y productivo; mientras que dejamos el concepto de globalización para comprender tanto a este como al complejo de ideas que se integran en una particular concepción del mundo y que no existía en etapas anteriores del capitalismo histórico. Desde esta perspectiva, la globalización integra tanto el proceso económico que caracteriza la evolución contem- y el auge de la «regionalización» y el «regionalismo» ${ }^{5}$.

El contexto internacional, transitando más de una década de post guerra fría, vivía el proceso de construcción de un nuevo orden mundial, bajo la preeminencia de los Estados Unidos como la única superpotencia. Las condiciones que habían caracterizado al sistema internacional durante los doce años anteriores, frente a las cuales la política exterior norteamericana respondió con tendencias contrapuestas entre el unipolarismo y el multipolarismo ${ }^{6}$, se reforzaron fuertemente hacia el unipolarismo, luego de los atentados del 11 de septiembre de 2001. Los Estados Unidos, bajo la presidencia de George

poránea de la economía capitalista mundial, como el sistema de ideas y concepción del mundo que acompañan a la mundialización capitalista. Cfr. Bernal-Meza (1996;1997;2000).

5 La experiencia señala que actualmente se usan de manera indistinta los términos «regionalismo»y «regionalización» como sinónimos de integración económica, a nivel de regiones o subregiones de países, en el marco de la economía política mundial. Sin embargo, si bien la integración económica es un ejemplo de regionalismo, este expresa dimensiones más amplias y no necesariamente vinculadas a la integración económica. En este caso cabe su formulación como sustento de una política exterior o la aspiración de un grupo de Estados a configurar un subsistema internacional y, por esta vía, transformarse en un actor con identidad propia y distinta, más allá de la que representan cada una de sus partes integrantes. Cfr. BernalMeza (2009).

6 Para nuestra interpretación al respecto, cfr. Bernal-Meza $\left(2004 ; 2005^{\mathrm{a}}\right)$. 
Bush Jr. abandonaron la visión del internacionalismo liberal neo-kantiano, que había predominado en la política internacional de la administración de Bill Clinton. En ese contexto, América Latina perdió interés en la política exterior norteamericana, cuya preocupación se centró en la guerra contra el terrorismo islámico.

La política exterior norteamericana, en sus fundamentos epistemo-teóricos, pasó del soft power propuesto por Joseph Nye (2004) y adoptado por Clinton como mecanismo de seducción y atracción hacia su renovada visión del multilateralismo en condiciones de hegemonía, al hard power que la derecha republicana rescató de la tradición más dura del realismo norteamericano.

Como señaló un gran historiador, el corto siglo XX había terminado en 1991. En los años finales de la década de 1980 y en los primeros de la de 1990 terminó una época de la historia del mundo para comenzar otra nueva (HOBSBAWM,2007), que se cerraba con el fin de la guerra fría y se abría a un nuevo ciclo de utopía neoliberal. Fue esta transición la que justificó a un difundido autor afirmar «el fin de la historia», que diferenciaba entre aquellos Estados en que se impuso la democracia y el libre mercado y aquellos que seguían anclados en la historia. Fukuyama (1992) representaría el símbolo de la visión liberal, simplista y monocausal de las relaciones internacionales ${ }^{7}$; cosmovisión

7 Como dijo este autor, «la democracia liberal podía constituir el punto final de la evolución ideológica de la humanidad, la forma final de gobierno y que como tal que sería confrontada por la realidad de los hechos: un mundo fragmentado por las diferencias. Estas fueron advertidas por otros ideólogos de las relaciones internacionales, entre los cuales destacó Huntington (1993;1996), que fundamentaría las nuevas interpretaciones para el conflicto internacional y la lucha por el poder, basadas en las diferencias culturales y religiosas.

Así, Fukuyama y Huntington expresaron la imagen de un mundo fragmentado y conflictivo, que reflejaba la existencia de multipolaridades. Un contexto sistémico que los pensadores de la política exterior brasileña supieron captar para sustentar los fundamentos sustentadores de la nueva visión de su política exterior. Este sería el escenario en el cual se formularía el pensamiento teórico de la política exterior de Lula da Silva.

\section{Los CAMBIOS EN EL ABORDAJE TEÓRICO DE LA HEGEMONÍA ${ }^{8}$}

A pesar del cambio de época, que se identificaba con el fin del orden bipo-

marcaría el fin de la historia. Es decir que mientras las anteriores formas de gobierno se caracterizaron por graves defectos e irracionalidades que condujeron a su posible colapso, la democracia liberal estaba libre de estas contradicciones internas fundamentales» (Fukuyama,1992:11).

8 Las referencias a los distintos autores que se hacen a continuación tienen el objetivo de identificar trazos fundamentales de los debates, en relación con la influencia o reacción que pudieron tener o provocar sobre líneas de pensamiento teórico y político en Brasil y no reflejan la diversidad teórica existente en el período. 
Raúl Bernal Meza • El pensamiento internacionalista...

lar, los cambios en el abordaje teórico acerca de la interpretación del mundo y sus procesos habían comenzado antes, hacia finales de la década de 1970 y la siguiente. La academia norteamericana dominó los debates, entre los formuladores de la interdependencia (Keohane y Nye,1977) y la respuesta del neorrealismo estructural (Waltz,1979; y Gilpin, 1981); mientras como alternativas aparecían la teoría crítica (Cox, 1981)) y una renovada visión de la economía política de las relaciones internacionales que hacía parte de una tradición sistémico-estructural (Wallerstein,1974; Arrighi,1994;1996).

Por otro lado, reafirmando la influencia del liberalismo kantiano - ya presente en el pensamiento de la interdependencia- el papel de las instituciones y la cooperación en el ordenamiento sistémico (Keohane,1988,1993; Krasner,1986; Hurrell,1992), parecía influir predominantemente en las propuestas de política exterior de lo que años después sería el período de la administración Clinton.

Una visión que contribuyó fuertemente a fragmentar el mundo que - supuestamente- estaba uniendo el «nuevo orden» y la "globalización» fue el paradigma civilizatorio, propuesto por Huntington $(1993 ; 1996)$. La diplomacia brasileña respondió a este clivage cultural fortaleciendo la idea de un «Brasil multicultural y multirracial».

Por último, un elemento teórico importante por su influencia en el modelo brasileño ideal de Estado que debería servir como el instrumento para la inserción en el nuevo contexto global sería el estado comercial (Rosecrance,1986), al que ya se había identificado como fuente de importante influencia en la política exterior chilena (BernalMeza,2004) y la argentina del período de gobierno de Carlos Menem (19891999). En este último caso, en el realismo periférico, la formulación teórica de Escudé que influyó decisivamente en la política exterior argentina entre 1989 y 2003 (Escudé,1992;1995), había una fuerte influencia de Rosecrance, cuestión que el propio Escudé había reconocido expresamente ${ }^{9}$.

Toda esa producción de lo que muchos identificaron como la «escuela norteamericana», en la que seguía predominando la tradición realista, enfrentó el desafío de interpretar la naturaleza de los cambios que comenzaban a insinuarse en el sistema internacional. Pero las teorías dominantes provenientes de los Estados Unidos no supieron prever el fin de la guerra fría (Smouts,1998) lo que abrió espacios a las renovadoras ideas representadas por las escuelas europeas: la inglesa (Watson; Wight; Calvocoressi; Bull) y la francesa (Renouvin; Duroselle; Zorgbibe; Paillard), que abordaban en sus estudios la «sociedad internacional» desde la década de 1970, y que influirían en el pensamiento de los autores y académicos de lo que he denominado la «Escuela de Brasilia» ${ }^{10}$ (Cervo; Moniz Bandeira; Saraiva; Lessa), una comuni-

\footnotetext{
9 Ver Bernal-Meza (1994:192-193).

10 Bernal-Meza (2005); Cap. IX.
} 
dad epistémica cercanamente vinculada a Itamaraty.

De todos los debates que se produjeron en esos años, un punto central para entender lo que el presidente Lula haría en política exterior serían los debates entre unipolaristas y multipolaristas y las discusiones con aquellos que buscaban imponer determinadas visiones sobre la globalización; debate este último en el cual ingresarían también algunas líneas de la tradición estructuralista latinoamericana, como antiguos «dependentistas» (Dos Santos) los que la abordaban desde la perspectiva cultural (Ortíz) y algunos «neoestructuralistas» (Ferrer; Ianni). Entre estos últimos se encontrarían los nuevos aportes desde la periferia a las discusiones sobre la etapa contemporánea del capitalismo histórico, con autores como Tomassini, Ferrer, Rapoport, Bernal-Meza, autores de la academia chilena y predominantemente argentina, la mayoría de los cuales tendría una fuerte repercusión positiva en Brasil.

\section{CONTEXTO INTERNACIONAL Y REGIONAL DEL PERÍODO LULA}

\section{El escenario latinoamericano}

El contexto regional, en el cual asume la presidencia Luiz Inácio Lula Da Silva, particularmente en América del Sur, está marcado por el fracaso de la experiencia neoliberal. Un importante número de países están envueltos en una profunda crisis económica, social y política como consecuencia de la aplicación de políticas de apertura económica y desregulación durante la década precedente; mientras que en otros, sus gobiernos enfrentarían fuertes oposiciones a las mismas políticas, que conducirían a cambios drásticos en las alianzas gubernamentales. Bolivia, Argentina, Brasil, Ecuador, Uruguay y mucho más tarde Paraguay, se agregarían a Venezuela y Chile en el número de países en que alianzas de centro-izquierda, aunque con distintas políticas económicas, accederían al gobierno.

En síntesis, los escenarios eran muy diferentes a comienzos del siglo XXI de lo que habían sido durante la década de 1990. A una década de fuerte homogeneidad, de predominio del modelo normal o neoliberal como tipo ideal de Estado ${ }^{11}$; de políticas económicas adhesión a la agenda de valores hegemónicos universales o internacionalmente reconocidos ${ }^{12}$, tales como las normas democráticas a través del mundo, propias del discurso del internacionalismo liberal norteamericano, que justificaría las nuevas formas de intervención internacional y la reforma del principio de no intervención en la Carta de las Naciones Unidas; la promoción del liberalismo económico; la protección del medio ambiente y otros

${ }_{11}$ Para explicar e interpretar la política exterior brasileña y latinoamericana seguimos aquí los tipos ideales de Estado, desarrollados por Amado Luiz Cervo Cfr. Cervo $\left(2000 ; 2001 ; 2008 ; 2008^{\mathrm{a}}\right)$.

12 Según la definición de Vigevani et.al. (1999). 
que contribuyeron a promover las visiones liberales sobre la globalización y la interdependencia (Bernal-Meza,2000), políticas exteriores muy coincidentes y fuerte inclinación hacia Estados Unidos así como una visión de la integración sostenida en el "regionalismo abierto", seguida de una década de profunda heterogeneidad: con el modelo ideal de Estado (con presencia de modelos desarrollista, normal y logístico), políticas económicas; visiones sobre la integración y el regionalismo y vínculos con Estados Unidos. Temas como mayor o menor apertura económica, más o menos globalización, adhesión o rechazo al ALCA, cercanía u oposición a la política internacional norteamericana y modelo de regionalismo, pasaron a diferenciar profundamente a los países latinoamericanos.

Estos cambios implicarían también una profunda revisión de las respectivas políticas exteriores y, en especial, de la visión de mundo, paradigma o doctrina que las sustentaban y también una reformulación de los modelos de regionalismo (Bernal-Meza, 2009). «Bolivarismo y socialismo del siglo XXI» (en Venezuela, Ecuador, Bolivia y Nicaragua); bilateralismo y alineamiento con Estados Unidos (Colombia, México); «multilateralismo» y «regionalismo abierto» (Chile); «nacionalismo de economía abierta o nacionalismo económico de libre mercado» (Argentina); "período especial en época de paz» (Cuba); «realismo y regionalismo sudamericano» (Brasil), pasaron a sustituir, como formulaciones, pre-teorías y doctrinas, el pensamiento de una dé- cada en la cual habían predominado el neoidealismo kantiano, el globalismo subordinado, el neoliberalismo y el regionalismo abierto (Bernal-Meza,2009ª).

Paralelamente al abandono del paradigma de «potencia media» (México), la mayoría de los países sudamericanos (Venezuela, Bolivia, Ecuador, Argentina, Paraguay), se volcaron hacia políticas económicas más nacionalistas y estatizadoras, retornando visiones neoproteccionistas sobre la integración económica que, sin ser dominantes, comenzaron a confrontar con la anterior visión predominante de «regionalismo abierto» y que sería también la predominante en la visión política brasileña, aun cuando esta sería matizada por el pragmatismo. Así, la visión semiproteccionista del modelo MERCOSUR sería sustituida por la perspectiva más pragmática y flexible de la UNASUR.

Simultáneamente y coincidente con lo anterior, las dos administraciones de Lula da Silva se encontraron con dificultades derivadas de cambios radicales en las relaciones económicas internacionales de tres países - Bolivia, Ecuador y Paraguay- cuyos gobiernos adoptaron paradigmas de política exterior que implicaron o fueron consecuencia de cambios sustantivos en la concepción del tipo de Estado anteriormente vigente y su sustento bajo la tradición del pensamiento realista clásico.

La crisis del modelo neoliberal, que se extendió por gran parte de los países de la región condujo en la mayoría de ellos a una reformulación del tipo ideal de Estado, asociado a una reestruc- 
turación de la inserción en el sistema económico mundial. En la mayoría de los casos - Argentina, Venezuela, Ecuador- y en otros cuyos Estados no habían alcanzado aún la plenitud de su proceso de construcción nacional - como Bolivia y Paraguay- las nuevas alianzas gobernantes procedieron a una refundación, en el primer caso, o a una fundación, en el segundo, del modelo desarrollista. Así, bajo el criterio de recuperar o formar un capitalismo nacional, principalmente público (Venezuela, Bolivia, Ecuador), aunque también privado (Argentina, particularmente), surgió una variante neodesarrollista, con fuerte intervención estatal, que implicó la nacionalización de grandes empresas (gas, petróleo, energía eléctrica, aéreas y de servicios) y la creación de nuevas empresas estatales. Este modelo se caracterizaría por una política de «nacionalismo de economía abierta» o «nacionalismo económico de libre mercado», como sería el modelo argentino, o de formas más radicalizadas de nacionalismo económico, con influencias neomarxista como ha sido el caso de Venezuela y Bolivia (BernalMeza,2009a).

Solamente dos países avanzaron por el camino de la construcción del tipo ideal de Estado logístico: Chile y Brasil (Cervo, 2008). En la práctica y por el hecho de haberse lanzado por ese camino desde la época del neoliberalismo autoritario de Pinochet, el modelo chileno sería pionero, asumiendo las principales iniciativas y medidas de políticas públicas que caracterizarían al modelo logístico, como la formación de grandes grupos económico-financieros nacionales, la internacionalización de las empresas privadas, la captación de inversión extranjera directa, la exportación de capitales, la constitución de organismos estatales para apoyar la internacionalización de las empresas y la proyección externa de sus negocios y operaciones y el desarrollo de una sólida infraestructura aeroportuaria, de carreteras, telecomunicaciones e informática. Asociado a esto, la negociación internacional de una amplia red de tratados y acuerdos comerciales que facilitaran el acceso de la producción nacional a los grandes mercados mundiales (Estados Unidos, Unión Europea, Japón, China, etc.).

Sin embargo, a diferencia del modelo brasileño, el proto-Estado logístico chileno no impulsó la creación de nuevas empresas estatales ni tampoco mixtas.

\section{a) La revisión de las estrategias post-neoliberales: el modelo ideal del Estado logístico}

Este modelo de inserción postdesarrollista, formulado teóricamente por Amado Cervo, tiene como objetivo superar las asimetrías entre las naciones elevando la situación nacional al nivel de los países avanzados, transfiriendo a las sociedades las responsabilidades del anterior "Estado empresario»y ocupándose ahora de secundar a la sociedad en la realización de sus intereses. El Estado logístico imita el comportamiento de las naciones avanzadas, 
particularmente de Estados Unidos, país que se considera el prototipo del modelo. Su componente de política exterior en el campo de las relaciones económicas internacionales apunta a reducir la dependencia tecnológica y financiera, promover la innovación productiva y otras iniciativas que disminuyan la vulnerabilidad externa. Internamente, busca reforzar el núcleo económico estructural nacional para poder impulsar su internacionalización (Cervo, 2008a:82-90).

«A ideología subyacente ao paradigma logístico associa um elemento externo, o liberalismo, a outro interno, $\mathrm{o}$ desenvolvimentismo. Funde a doutrina clássica do capitalismo como o estruturalismo latino-americano. Admite, portanto, operar na ordem do sistema ocidental, recentemente globalizado (Cervo, 2008a:85). O comportamento do Estado logístico descola, se da teoria realista das relações internacionais. Supõe concluída a fase desenvolvimentista, centrada no interno, e projeta a internacionalização econômica. Põe em marcha dois componentes de conduta advogados pelos realistas: a construção de meios de poder e sua utilização para fazer valer vantagens comparativas, não mais naturais, mas intangíveis, como ciência, tecnologia e capacidade empresarial» (Cervo, 2008a:87).

b) Evo Morales: la reformulación del Estado boliviano y su impacto en la política brasileña

La llegada al gobierno de Evo Morales en enero de 2006 modificó profundamente el contexto de las relaciones bilaterales con Brasil y Argentina y también el contexto de las relaciones intrarregionales. Si bien la lógica de toma de decisiones y de conducción política diferenciaría rápidamente a Evo del resto de prácticas gubernamentales sudamericanas sostenidas en la visión hegeliano-realista del poder, sería su política de nacionalización de hidrocarburos lo que marcaría el eje de las primeras disputas con Brasil desde el conflicto por Acre.

La refundación del Estado llevada adelante por Evo implicó la adopción de una toma de decisiones de carácter colectivo y bajo el criterio de la «representatividad», que beneficiara a la gran mayoría de la población, de origen indígena, históricamente excluida de las estructuras de poder. Uno de los instrumentos para proveer de recursos al proyecto del nuevo Estado fue la política de nacionalizaciones (fundamentalmente en el área de los hidrocarburos y energéticos), recuperando el control estatal sobre yacimientos y refinerías y afectando con ello los intereses de capitales brasileños (Petrobras).

Particularmente en el caso boliviano —que es el ejemplo más avanzadopero también presente, con diversos niveles, en los casos de Ecuador y Paraguay, la reformulación de la visión del Estado que llevaría adelante el nuevo gobierno de base popularindígena confrontaría abiertamente con la concepción realista de raíz hegeliana dominante en Brasil, como también en otros países de la región. 
El impacto que produjo la nacionalización de los hidrocarburos abarcó no solo el sistema de relaciones bilaterales con Brasil sino también las características de la integración regional, vis-à-vis la inserción globalizada. Implicó la inclusión del tema energético como prioridad de la agenda sudamericana; lo que llevó a la diplomacia de Lula a adecuar la cancillería a las nuevas realidades derivadas de este escenario. Así, en abril de 2007, el Ministerio das Relações Exteriores creó la Secretaría de Energía y la llevó al segundo lugar de importancia en la estructura jerárquica de las dependencias de Itamaraty.

El tema energético modificó las prioridades temáticas regionales, influyendo también en las relaciones de otros países - como fue el caso del gas, entre Argentina y Chile- debido a que otros factores externos, como el aumento de los precios internacionales y la caída de la producción de petróleo y gas en la Argentina, pusieron a los países productores (Bolivia, Venezuela, Ecuador) en el centro de la atención de la diplomacia de integración.

c) La nueva política energética sudamericana y su impacto en Brasil

Desde el año 2000 y hasta mayo de 2006 - fecha de las nacionalizaciones bolivianas de los hidrocarburosexistieron dos modelos de integración energética, el liderado por Brasil, vía la IIRSA, en la cual los principales protagonistas eran los sectores privados, $\mathrm{y}$
PETROAMÉRICA, la iniciativa venezolana, que impulsaba una mayor intervención estatal.

Durante el período 2000-2005 no hubo grandes diferencias y el gobierno venezolano aceptó y apoyó las iniciativas energéticas brasileñas propuestas en el marco de la IIRSA. Fue a partir de las nacionalizaciones de Evo Morales que ambos proyectos comenzarían a distanciarse, evidenciando diferencias en la concepción de la economía política de la energía.

Mientras la iniciativa brasileña mantenía la propuesta IIRSA, con presencia empresaria excluyente de Petrobras por parte del país, la propuesta venezolana apuntaba a la creación de una empresa multinacional latinoamericana y caribeña, conformada por el conjunto de empresas estatales de la región dispuestas a participar. Sería así el gobierno de Venezuela, enfrentando a Brasil, el que plantearía la integración regional energética, y en general toda integración, como un asunto de los Estados y no de los privados.

El gobierno de Lula respondió fortaleciendo Petrobras y diversificando la búsqueda de fuentes de provisión energética, internas e internacionales. Pero una de las iniciativas que profundizaría las diferencias respecto de la economía política energética sería el fortalecimiento brasileño del desarrollo de biocombustibles, firmando con Estados Unidos un memorando de entendimiento para la cooperación en dicha área. El tema de los biocombustibles terminaría por oponer a Brasil a importantes o potenciales 
Raúl Bernal Meza • El pensamiento internacionalista...

productores regionales, como Argentina y Venezuela.

La perspectiva estratégica brasileña de los biocombustibles tuvo por objeto diluir o desplazar el eje de la importancia que tienen el petróleo y el gas para el proceso de integración y de sus países proveedores en la infraestructura regional. Pretende impulsar los biocombustibles como eje de una estrategia energética de inserción de la región en el mundo, mediante un modelo de especialización complementaria, pero ahora con Estados Unidos. La estrategia norteamericana comenzó a aprovechar el interés nacional brasileño para evitar la convergencia regional, particularmente de Venezuela, Bolivia, Ecuador y Argentina, frente a los intereses de sus empresas transnacionales y de los organismos multilaterales como la OMC. Al desarrollarse el área de los biocombustibles bajo esta perspectiva se apoyaba una opción de mercado desregulado que tiende a separarse de la planificación necesaria para toda la matriz energética regional. De esta forma, la política energética de Lula generó una línea de diferenciación respecto de lo que se interpretó como un «eje sudamericano», que excluía a Brasil (Quintanar, 2009).

\section{El universo paradigmático} de la política exterior brasileña y el gobierno Lula: realismo, regionalismo y Estado logístico

Las visiones sobre la política mundial y la globalización de F.H. Cardoso y Lula da Silva fueron enfrentadas y opuestas. El primero había adherido al neoliberalismo heredero de la tradición liberal, en tanto Lula y sus colaboradores adherirían al neorrealismo, proveniente de la tradición realista. Así, mientras Cardoso confió en la configuración idealista de un nuevo orden multipolar, con el desarrollo progresivo de unas relaciones internacionales más justas y armónicas, Lula no se separó de la visión jerárquica del poder mundial y fue escéptico frente a la visión idealista de un mundo global más pacífico, cooperativo y armonioso.

La oposición entre ambas visiones sobre la política internacional ya se había reflejado en el debate entre dos tendencias: la «hemisférica bilateral» y la «globalmultilateral» (Cervo y Bueno, 2002). La primera, que promovía la alianza con Estados Unidos, fue predominante en los gobiernos de Cardoso. La segunda sería dominante en los gobiernos de Lula y con ella Brasil retornó al universalismo selectivo retomando sus alianzas y vínculos con India, China, Sudáfrica y Rusia.

Bajo la tendencia «hemisféricabilateral» Brasil adhirió, como otros países con gobiernos neoliberales de la región, a la agenda de valores hegemónicos universales o internacionalmente reconocidos, agenda que sin rechazar de plano Lula subordinó a los temas tradicionales del desarrollo económico y la seguridad.

Sin embargo, ambas líneas de pensamiento se acercaron en un punto de confluencia: en la necesidad de 
promover la cooperación internacional para avanzar en objetivos de paz, desarrollo y justicia o equidad, interna e internacional. Este aspecto ha sido importante porque marca la coincidencia en el papel que le correspondía jugar a Brasil —dados sus recursos y capacidades - en el management del ordenamiento mundial y su aporte a la «gobernabilidad internacional» (international governance); aunque diferirían profundamente sobre la viabilidad de la «interdependencia económica». Al final de su gobierno, Cardoso expresó su frustración respecto del concepto de globalización asimétrica ${ }^{13}$ poniendo a la integración sudamericana como base para enfrentarla y favorecer el diálogo con la Unión Europea mientras que los realistas brasileños siempre vieron la integración, a partir del MERCOSUR, como una base de poder para contrarrestar el dominio y la influencia norteamericanos en Sudamérica ${ }^{14}$.

El grupo formulador de política exterior de Lula adhirió a la visión de Joseph Nye sobre el mundo multipolar, una interpretación del orden en la que coincidirían tanto el pensamiento liberal (Lafer) como el realismo nacionalista brasileños (entre ellos, Moniz Bandeira y Pinheiro Guimarães). En el primer caso, porque compartían una matriz neo-kantiana y en el segundo, porque el multipolarismo era funcional a la concepción de lo que como go-

13 Cfr. La Nación y Clarín, Buenos Aires, 5 de enero de 1999.

14 Cfr. Al respecto, Moniz Bandeira (1996); Bernal-Meza (2000). bierno aspiraban a hacer en la política mundial. Para ambos, el multipolarismo del nuevo orden emergente permitía un espacio de acción para un poder intermedio como Brasil.

La visión de Celso Lafer, pensador liberal y canciller de Cardoso, fue retomada por los formuladores de política exterior de Lula. Su pensamiento teórico es identificable en dos etapas. En la primera (1996), cuando acompaña con sus ideas a F.H. Cardoso fundamenta la visión del nuevo contexto sistémico comparando las esencias ${ }^{15}$ entre los órdenes de la guerra fría y el posterior y en la segunda, al final del gobierno de Cardoso (2002), intenta sostener la continuidad de la política exterior brasileña mediante la apelación a las «identidades» que caracterizarían al Brasil (Bernal-Meza,2005).

Celso Lafer buscó recuperar y aggiornar principios tradicionales de la política exterior para fundamentar el cambio para adecuarla a lo que consideró como el «nuevo contexto sistémico» que se daba en los años noventa y en el cual debía insertarse el país. Lo novedoso resultó ser la apelación a la "credibilidad y la confiabilidad externa»-en coincidencia con la comunidad epistémica argentina que apoyó el realismo periférico- como condiciones de acceso al mundo, en los tres campos

15 Aun cuando no era nueva la idea del cambio de esencias o la identidad ontológica de los cambios. Este autor habló de los mismos en sus libros Clave del Nuevo Orden Mundial (1991) y América Latina en la Economía Política Mundial (1994). 
integrados de la vida internacional: el estratégico, el económico y el de los valores (Lafer,1996:72). La idea fundamental era que un país de características continentales, como Brasil, debía revisar y adecuar su visión del mundo precedente y que fuera dominante bajo el modelo desenvolvimentista, entre 1930 y 1990.

En su trabajo de 2001, Lafer $(2002)^{16}$ fundamentó su visión respecto del nuevo contexto sistémico comparando las esencias entre el orden de la guerra fría, caracterizado por las «polaridades definidas» y el actual en transición, de «polaridades indefinidas»; para luego señalar las continuidades de la política exterior brasileña, mediante la apelación a las identidades que caracterizarían a este país. ${ }^{17}$

El tema de las esencias señalaba para él que el sistema internacional había pasado de «un período de polaridades definidas» a otro de "polaridades indefinidas». Mientras el primero reflejaba la existencia de un sistema bipolar, en el segundo las antinomias se presentaban en cada uno de los componentes esenciales del orden sistémico anterior, dando lugar a un escenario multipolar en el cual había un espacio de acción para una potencia emergente como Brasil. Un contexto donde había que dar un sentido predominantemente económico

16 Versión original en portugués: A identidade internacional do Brasil e a política externa brasileira: passado, presente e futuro, Ed. Perspectiva S.A.

17 Un análisis más extenso de las ideas de este autor puede verse en Bernal-Meza (2005). a las parcerías internacionales (Lafer,1992) y una adhesión a la «agenda de valores universalmente aceptados», bajo las lógicas de la globalización (en su visión liberal) y la fragmentación (de las identidades, de la secesión de los Estados, de los fundamentalismos, de la exclusión social, etc.) que diluía las lógicas del viejo y clásico orden westfaliano.

Es evidente que en la visión de un mundo de "polaridades indefinidas» había un espacio para la inserción en ascenso del Brasil en la estructura de poder mundial. Esta visión congraciaba las ideas más liberales, que representaba la política del gobierno de Cardoso y que él integró como ministro de relaciones exteriores, con la tradición realista de Itamaraty. Sosteniéndose en los modelos de análisis histórico de Renouvin y Duroselle ${ }^{18}$ que ponen de relieve la existencia de "fuerzas profundas» entre los factores de persistencia de la inserción internacional de un país, Lafer apeló al concepto central de identidad nacional para explicar las continuidades y cambios en la política exterior brasileña.

Esa identidad nacional es la fuente de la diferenciación, también del nacionalismo. Sus componentes - la herencia histórica y el significado de la identidad internacional en un mundo globalizado, Brasil como un país de escala continental, el contexto de la

18 Cfr. Renouvin Pierre y Jean-Baptiste Duroselle (1991), Introduction à l'histoire des relations internacionales, Paris, Colin; $4^{\mathrm{a}}$ ed. 
vecindad, Brasil en el eje asimétrico del sistema internacional y la visión nacionalista de la búsqueda del desarrollo, constituyen los elementos que justifican la necesidad de diferenciar al Brasil del resto de países como los de América del Sur- permiten justificar las rupturas y las tendencias de largo plazo de la política exterior y disocian el régimen político de la formación y formulación de la política exterior.

La paradoja es que la visión de la política internacional de Lula ha sido cercana al neoliberalismo cuando creyó que la cooperación, a través de las instituciones y los acuerdos internacionales (Naciones Unidas, OMC, G20, etc.), podía morigerar los efectos de la anarquía y la imposición del poder imperial, pero también ha sido puramente realista cuando persiguió la construcción de alianzas para enfrentar el desafío que al ascenso de nuevas potencias le impone la hegemonía. Así puede comprenderse su preocupación por integrar e impulsar el grupo BRIC —o la construcción de un contrapoder de emergentes- que desafía el poder institucionalizado ${ }^{19}$. Con esta cooperación se buscó mejorar la posición relativa del Brasil en la estructura de poder mundial mientras a través de la integración sudamericana aspiraba a mantener la posición de superioridad frente al resto de los países sudamericanos (Moniz Bandeira,1996; Bernal-Meza,1999;2000;2008; Souto Maior,2006; Soares de Lima,2008).

19 Respecto de la aplicación del concepto de «contrapoder», cfr. Dupas (2005) y Cervo (2008).
La percepción de flaqueza y debilidad fue sustituida por una re-evaluación del papel de Brasil como potencia media y nación emergente que precisaba de una diplomacia de alto perfil, adecuada a sus capacidades y necesidades (Pecequilo, 2008:143). La diplomacia «presidencialista y personalista» sería sustituida por la «diplomacia de la nación» (Cervo,2002), fortaleciéndose la visión de Brasil como gran país. En palabras de su canciller: «o Brasil não é um país pequeño. Não tem e nem pode ter uma política externa de país pequeño» (Amorim,2007:7).

Un elemento muy importante en la evolución del pensamiento sustentador de política exterior sería la «formación de conceptos en relaciones internacionales», desarrollada por el profesor Amado Cervo.

Los conceptos - brasileños- reemplazarían las macro teorías de (supuesto) alcance universal, elaboradas por el pensamiento académico de los «centros», fundamentalmente Estados Unidos.

Desde una perspectiva metodológica - que ha tenido una clara aplicación en la política exterior de Lula- es interpretada como una elaboración conceptual que sustituye la elaboración teórica ajena, porque se está en un período sistémico de "polaridades indefinidas».

El principal concepto formulado al respecto fue el de "Estado logístico». Este sistema de ideas brinda una orientación estratégica para la dinámica de Brasil en las arenas internacionales y fundamenta su expansión en términos 
Raúl Bernal Meza • El pensamiento internacionalista...

de influencia. Además, involucra un conjunto de concepciones compartidas por los sectores dirigentes sobre los roles de la estructura estatal. En este sentido, el Estado «ejerce la función de apoyo y legitimación de las iniciativas de los otros actores económicos y sociales» (Cervo, 2008; 2008 ${ }^{\mathrm{a}}$ ) y supone para este una serie de tareas que le permitan transformarse en una plataforma de despegue, principalmente económico, pero también político, de los agentes públicos y privados del país.

Es posible identificar dos dimensiones de este enfoque: a) como una serie de percepciones sobre las transformaciones recientes del sistema internacional y sobre el rol de Brasil en los escenarios mundiales y b) como un grupo de políticas que orientan la estrategia de desarrollo interno y de relaciones internacionales.

Las imágenes del orden internacional se relacionan con el reconocimiento de la mundialización, la interdependencia global y el regionalismo, como los procesos dinámicos que marcan al mundo contemporáneo (Sombra Saraiva y Cervo, 2005). Otro factor significativo es la convicción de la pérdida de la estabilidad hegemónica unilateral por parte de los Estados Unidos de América y, por consiguiente, el nacimiento de un orden mundial con base en el multilateralismo, que implicaría una estructura histórica distinta de la anterior. Con este nuevo orden internacional surgirían, asimismo, responsabilidades para los países, y otros actores, de la aristocracia ejecutiva que participarían de la toma de decisiones en una suerte de gobernanza global, o global governance ${ }^{20}$ (Masera, 2010).

El concepto de Estado logístico permite, desde el punto de vista de las concepciones sobre el desarrollo económico, desligar a Brasil de la visión que los teóricos de la dependencia tienen sobre el «centro» y la "periferia». Brasil no es periferia. Está en una posición intermedia, transicional, en condiciones de alcanzar al selecto grupo de Estados que comandan los patrones de status, riqueza y poder del sistema mundial ${ }^{21}$. La élite que conduce ahora al Estado brasileño busca mejorar la posición relativa del país aceptando la competencia y, al mismo tiempo, buscando

20 Se menciona como clave el documento "Common Responsibility in the 1990s.: the Stockholm Initiative on Global Security and Governance» de 1990. De otra parte, el término gobernanza se encuentra ya aceptado por la comunidad académica, particularmente después de la publicación del documento de la Unión Europea (Cfr. Comisión de las Comunidades Europeas, op. cit., 2001). En los estudios internacionales ha sido importante el surgimiento del «International Risk Governance Council» (IRGC, Ginebra, Suiza desde 2003). Otro de los think tanks reconocidos es el «Instituto de Investigación y Debate sobre la Gobernanza», con sede en París <www. institut-gouvernance.org>, el cual actúa, además, como red sobre el tema. En el ámbito regional es el Instituto de «Estudos Econômicos e Internacionais» (IEEI) de Brasil, uno de los centros multidisciplinarios de reflexión y análisis de cuestiones económicas e internacionales que más han desarrollado las implicaciones del concepto de gobernanza global.

21 Cfr. Al respecto, Arrigui (1998), Aymard (1985). 
una política de equiparación, tal como se explicaría en la participación y las posiciones políticas frente al FMI y en el G20.

El Estado logístico propende a la acumulación de atributos de poder para reforzar lo que Cervo denomina el «núcleo económico nacional duro" (Cervo, 2008a: 87). Esta estrategia se constata en la búsqueda de diversos objetivos de política externa: consolidación de prestigio, de liderazgo en los ámbitos de concertación regionales y de presencia clave en foros internacionales como el G20, etc.

\section{Realismo y acumulación de poder}

Brasil se transformó en el único país latinoamericano ${ }^{22}$ en re-adoptar el realismo como teoría o paradigma de política exterior. Bajo esa visión, los formuladores de política, tomadores de decisión e influyentes miembros de la comunidad epistémica que les acompañan, consideraron a Brasil como el único actor que podía competir con Estados Unidos por la «influencia hegemónica» en América del Sur ${ }^{23}$. La

22 Para una visión general de los paradigmas dominantes de política exterior en América Latina, cfr. Bernal-Meza (2009a).

23 Ver al respecto, por ejemplo, Samuel Pinheiro Guimarães y L. A. Moniz Bandeira. Mientras el primero señala que Brasil es el «único rival possivel à influência hegemônica dos Estados Unidos" (Pinheiro Guimaräes,1999:121); el segundo señala que, frente a la expansión de intereses estratégicos de Estados Unidos en América del Sur, «o Brasil não pode deixar de idea de hegemonía había evolucionado desde la "aspiración al liderazgo", consolidada desde mediados de la década de 1990 (Bernal-Meza,2000), hacia un convencimiento sobre el liderazgo mismo, que comenzó a proyectarse sobre la concepción del papel que le correspondía desempeñar a Brasil en la escena regional. Es un hecho comprobado que en los años de Lula Brasil se involucró internacionalmente de modo mucho más activo y multilateral de lo que había ocurrido durante la década de los años noventa, tanto en las relaciones económicas internacionales como en los asuntos de seguridad, que demostraron una nueva actuación internacional, asumiendo cada vez más dimensiones globales. Interpretado en términos neo-realistas: para obtener más poder, a Brasil le interesaba modificar su propia posición en el sistema internacional (Schirm,2007).

Dos agrupaciones de potencias emergentes pasaron a dominar las preferencias como mecanismos para la reformulación del orden global a través del multilateralismo: los BRIC (Brasil, Rusia, India y China) e IBAS (India, Brasil y África del Sur). Mientras el segundo reafirmaba el retorno a África desde una perspectiva estratégica del

reequipar e modernizar suas Forças Armadas, particularmente a Marinha de Guerra, com a construção do submarino nuclear, e adquirir mais e mais autonomia e autosuficiência na produção de material bélico, condição essencial para alcançar o status de grande potência, integrando toda a América do Sul» (Moniz Bandeira, 2009:75). 
Raúl Bernal Meza • El pensamiento internacionalista...

hemisferio austral, el primero representaba el grupo de poder emergente global. La presencia en ambos grupos se comprende porque Brasil quiere estar presente en todas las mesas de negociación del mundo, como lo está en la OMC y el G20 y quiere estarlo en el Consejo de Seguridad, donde se deciden las reglas, muchas de las cuales pueden serle perjudiciales.

Para Brasil, los BRIC son muy importantes, porque en la nueva visión sobre el orden y el poder globales, esa agrupación le transfiere importancia (jerarquía) en la política internacional y coinciden en su deseo de ser influyentes en ella, aumentando su valor jerárquico relativo.

Liderazgo, aspiración a un reconocimiento como potencia mundial, acumulación de recursos de poder, ponían en evidencia objetivos e intereses globales de la nueva política exterior. Como señaló un embajador «simplificadamente, pode-se dizer que a idéia—chave suibjacente à nossa atual política regional é a construção de uma base subcontinental tão ampla e sólida quanto possível, de modo a firmar a liderança brasileira na América do Sul, o que deveria facilitar, no âmbito mundial, o exercício de uma política de potência emergente» (Souto Maior,2006:54).

Sin embargo, la lógica de su estrategia global no ha sido homogénea: en el caso de la cooperación sur-sur con los países sudamericanos, Brasil asume una estrategia cercana al patrón de hegemonía, mientras que en aquella
Sur-Sur internacional-multilateral, asume un comportamiento de liderazgo colectivo, en asociación con otros países igualmente system-affecting ${ }^{24}$, como India y China (Saraiva, 2007).

\section{LOS CAMBIOS EN LA CONCEPCIÓN DEL REGIONALISMO Y LA INTEGRACIÓN}

La línea, aparentemente lógica de acumulación de poder por vía de la regionalización, ha sido significativamente cambiante en los últimos veinte años tanto en la visión sobre su actor -el tipo de Estado- como de su sustento, la política exterior y su fundamento teórico e ideológico.

Lula encontró una gran dispersión de modelos de regionalismo y estrategias de inserción económica en el continente, la que enfrentó impulsando una propuesta pragmática y flexible - la Comunidad Sudamericana de Naciones, hoy UNASUR-, con la cual buscó la inclusión de los cinco esquemas arancelarios existentes en América del Sur (ALBA, MERCOSUR, CARICOM, Chile, Comunidad Andina de Naciones).

Brasil contó para esta estrategia con el decidido apoyo del gobierno chileno de Michelle Bachelet, también lanzado a una estrategia multilateralista y flexible, con el cual compartían -aunque

24 Es decir, que disponen de recursos suficientes para - junto a la intervención internacional activa- afectar el encaminamiento de ciertos temas de política internacional (Soares de Lima, 2005). 
bajo políticas económicas distintas-el modelo del «Estado logístico».

Un elemento clave del nuevo realismo brasileño ha sido la adhesión de las presidencias de Lula al concepto de «esferas de influencia», dividiendo América Latina en una zona caribeña, centroamericana y sureña del norte (México), toda ella dentro de la esfera de influencia norteamericana, y otra zona, la sudamericana, bajo la influencia de un MERCOSUR en expansión, cuyo eje dinámico de poder es el Brasil. No es necesario profundizar sobre esta reflexión: baste señalar que los documentos de política exterior de Itamaraty dejaron de hablar de "América Latina» como región hace ya más de un lustro (Bernal-Meza,2008). Al respecto, la percepción argentina, según la cual el entonces presidente Kirchner rechazaba la Comunidad Sudamericana de Naciones, era que esta "podría limitar al MERCOSUR y resulta perfecto para la estrategia brasileña de crear una América Latina sin México». ${ }^{25}$

El regionalismo brasileño, bajo Lula, está en relación estrecha con la concepción logística del Estado. Impulsa la integración productiva a través de la infraestructura, la energía y las inversiones brasileñas; mientras que, en el plano global ha forjado coaliciones que reforzaran el papel del Brasil como actor «global».

25 Morales Solá, Joaquín, «Los desafiantes objetivos de Brasil», en La Nación, Buenos Aires, 5 de mayo de 2005, p. 1.
EL RETORNO DE LA VISIÓN "LATINOAMERICANA Y CARIBEÑA» EN LA POLÍTICA EXTERIOR

Como han señalado diversos autores, la política exterior brasileña abandonó la idea de una América Latina como expresión de una "unidad regional» y subsistema a mediados de la década de $1990^{26}$.

Hacia el final de su gobierno, F.H. Cardoso ya había puesto a Brasil en oposición a Estados Unidos, en relación con la negociación de un acuerdo hemisférico de libre comercio y separado a Sudamérica del resto de América Latina. En ese esfuerzo por hacer de Sudamérica el entorno natural del Brasil, impulsó en el año 2000 la creación de una "Comunidad Sudamericana de Naciones» (CSN, hoy UNASUR), que era una forma más cooperativa del viejo proyecto del ex presidente Itamar Franco de crear un acuerdo de libre comercio sudamericano, el ALCSA, de 1993. Brasil estableció con el MERCOSUR una línea divisoria en el hemisferio americano: mientras consideró a América Central y Caribe una zona de influencia norteamericana, puso a América del Sur como zona de influencia del MERCOSUR. Esta visión sobre la existencia

26 En la última edición (en prensa) del libro Relações Internacionais da América Latina: velhos e novos paradigmas. São Paulo: Saraiva ( $\left.3^{\mathrm{a}} \mathrm{ed}\right)$, Capítulo 8 -AMÉRICA DO SUL NO SÉCULO XXI: CONSTRUÇÃO E DISPERSÃO- Amado Cervo argumenta justamente sobre las razones de este retorno (originales cedidos por el autor). 
Raúl Bernal Meza • El pensamiento internacionalista...

de una división entre una América bajo la hegemonía norteamericana y otra más independiente, cuyo eje debía ser el MERCOSUR fue profundizada por el gobierno de Lula da Silva, porque en ella estaban implícitos elementos clásicos del realismo, que nunca estuvieron del todo abandonados por la dirigencia y el establishment de política exterior del país ${ }^{27}$ (Bernal-Meza,2008:31-32). Durante su primer gobierno, el Presidente brasileño definió a América del Sur como el punto de partida para una nueva inserción de Brasil en el sistema internacional (Soares de Lima, 2008:99).

Lula da Silva iría aún más allá. Para ello - y sin la aprobación de Argentina- puso al MERCOSUR como núcleo de una integración más amplia, atrayendo a la Comunidad Andina de Naciones y a aquellos otros que se habían mantenido fuera de los esquemas sudamericanos, como Chile ${ }^{28}$, Suriname y Guyana. Este es el origen de la actual Unión de Naciones Sudamericanas (UNASUR); un acuerdo de cooperación e integración más flexible, centrado en el desarrollo de la infraestructura a través del proyecto IIRSA ${ }^{29}$.

La visión de una América Latina que no constituía una región única y

27 Cfr. Sennes (1999); Bernal-Meza (2000;2002);

28 Nos referimos a una condición de «socio pleno", la cual Chile solo ha mantenido con la Asociación Latinoamericana de Integración (ALADI).

29 Integración de la Infraestructura Sudamericana; proyecto impulsado al final de su mandato por Fernando H. Cardoso. homogénea y que justificaba la diferenciación respecto de Sudamérica, fue defendida fuertemente por diplomáticos y académicos brasileños de las relaciones internacionales. El desinterés por lo que ocurría con México en las relaciones intrarregionales enfrentó a Lula y a algunos de sus asesores con los gobiernos de Lagos (Chile) y Néstor y Cristina Kirchner (Argentina), para los cuales no podía dejarse de lado al país azteca de cualquier estrategia subhemisférica y que siempre consideraron a México como parte natural de una América hispano-lusitana en busca de la unidad.

Sin embargo, Brasil retornó a América Latina y Caribe durante la segunda presidencia de Lula. Ese retorno se ejemplificó en las visitas que el presidente brasileño hizo a México y en los encuentros que convocaron a Brasil y a países de la CARICOM, proceso que había comenzado en 2007, cuando su gobierno comenzó a desplegar su influencia en América Central a través del tema de los biocombustibles.

El avance sobre ambas subregiones comenzaría a formar parte de la estrategia de Lula por expandir la presencia e influencia del país en todo el mundo. El interés reforzaba la idea de que Brasil estaba comenzando a disputar a Estados Unidos y a México la influencia en dichas áreas. Sin embargo, la relación con este último país es ambivalente, pero no contradictoria: primero había dejado a México, la América Central y el Caribe; ahora compite con este, pero también se asocia comercialmente, a 
través de los acuerdos en el sector de la industria automotriz.

La razón del retorno estaría, no obstante, en la modificación de la visión sobre el futuro de una Sudamérica escindida y bajo el liderazgo brasileño. Lula da Silva fue a América Central y Caribe porque América del Sur se complicó demasiado con la llegada al gobierno de presidentes como Morales, Correa y Lugo. Así, su política exterior modificó la visión «sudamericanista» anterior y ahora ampliaba su interés hacia América Central, América del Norte (México) y Caribe.

La nueva visión es que fracasó la integración económica, política y de seguridad, a pesar de los acuerdos alcanzados en la UNASUR, porque en estos temas hay muchos desentendimientos, que se agregan a los ya existentes con Venezuela y Argentina y porque los gobiernos de Bolivia, Ecuador y Paraguay, además de las políticas de nacionalismo económico de otros países, frenaron la expansión de las empresas brasileñas. En definitiva, Brasil regresa a "América Latina» porque fracasó el proyecto «América del Sur».

\section{REALISMO, LIDERAZGO Y ACUMULACIÓN DE PODER}

Entre los aspectos que refuerzan la fuerte influencia (neo) realista y la acumulación de recursos de poder en el pensamiento del gobierno Lula pueden señalarse los siguientes:
- La utilización de conceptos y categorías propios de esta corriente teórica en el discurso y los análisis de política exterior. El ejemplo más evidente está en la aplicación de conceptos como «zonas de influencia» y "geopolítica", en las argumentaciones de diplomáticos y académicos más cercanos al gobierno ${ }^{30}$.

- La preocupación por delimitar «esferas de influencia» condujo a abandonar el concepto de "América Latina" como región homogénea y su sustitución por dos regiones muy definidas: América del Norte y Central, junto a Caribe, de una parte, $\mathrm{y}$ "Sudamérica», de otra.

- El desarrollo de su propio modelo de «regionalismo», la Comunidad Sudamericana de Naciones, luego UNASUR (Bernal-Meza, 2009), que excluyera a otras potencias hemisféricas (Estados Unidos) o regionales (México) de un liderazgo sudamericano.

- El esfuerzo por crear, integrar y fortalecer alianzas contra-hegemónicas: BRIC (Brasil, Rusia, India, China); Ibas G3 (India, Brasil, África del Sur); G20, en el marco de la OMC; y el impulso al G20, que sustituye al G8, pero que implican a su vez un reconocimiento de las estructuras jerárquicas del poder económico mundial, al aceptarse la continuidad del monitoreo del FMI

30 Ver, por ejemplo, uno de los últimos libros de Luiz Alberto Moniz Bandeira, editado por la Fundação Alexandre de Gusmão, del Ministerio de Relaciones Exteriores del Brasil: Geopolítica e Política Exterior (ensayos), Brasilia, 2009. 
Raúl Bernal Meza • El pensamiento internacionalista...

y contribuir a su fortalecimiento, mediante aportes y préstamos. ${ }^{31}$

- La decisión de convocar a la India y Sudáfrica a conformar el Grupo IBSA, con el fin de promover una intensiva cooperación tricontinental que funcione como contrapeso a la política unilateral de Estados Unidos (GABENDORFF, 2010).

- El énfasis en la seguridad; que se ha expresado tanto en el fortalecimiento del aparato militar (compras militares por 14.000 millones de dólares), la oposición a la presencia de Estados Unidos en bases militares colombianas, el cuestionamiento a la reactivación de la IV Flota de los Estados Unidos.

- El impulso a la creación del Consejo de Defensa Sudamericano (CDS), en el seno de la UNASUR, para establecer las bases de una nueva arquitectura de seguridad regional, por primera vez sin la tutela de Estados Unidos; indicio claro de la vocación de liderazgo sur-sur (GABENDORFF, 2010).

- El rechazo a otorgar autorización al Organismo Internacional de Energía Atómica para inspeccionar la planta de enriquecimiento de uranio de Resende.

- La persistencia en no desarrollar instituciones supranacionales en el

31 Por ejemplo, «a pesar del Acta de Copacabana (2004), respecto de las políticas a seguir frente al endeudamiento y los organismos multilaterales de crédito, las estrategias de Argentina y Brasil fueron antagónicas. Mientras Argentina exploró una variante heterodoxa de negociación, Brasil lo hizo de acuerdo con las más ortodoxas normas de los organismos financieros internacionales»; cfr. SIMONOFF (2010:420).
MERCOSUR, ni aceptar asignar poder a actores nacionales no estatales (como por ejemplo, los que integran el foro económico-social).

Paralelamente y en relación con la sociedad nacional (vínculo Estadosociedad civil), desde el punto de vista estructural e institucional, este paradigma pone en entredicho el intento por democratizar la formulación de la política exterior y el favorecer una creciente participación de otros poderes y sectores de la sociedad, en el esfuerzo por incorporar en la política exterior la expresión de otros intereses sectoriales más allá del Estado. Como han señalado dos autores, en Brasil persiste un modelo anacrónico de relaciones Estado-sociedad civil en general (Oliveira y Pfelfer,2006:422); aspecto que el realismo tiende a mantener, por su concepción centrada en el ambiguo principio del interés nacional.

\section{La evolución del modelo}

brasileño de Estado: el Estado logístico bajo el gobierno Lula

Mientras Cardoso buscó sustituir el «Estado desarrollista» por el Estado normal, Lula avanzaría en la implementación del tipo ideal de Estado logístico.

Con el fin de impulsar este modelo de inserción internacional para conducir al desarrollo, el gobierno de Lula formuló una estrategia política y económica cuyos aspectos centrales serían la búsqueda de un nuevo rol en el orden internacional — generando confianza 
entre las principales potencias mundiales acerca de la fiabilidad y mesura de su política multilateralista; buscando generar acuerdos con estas para fortalecer el sistema de las Naciones Unidas; promoviendo la idea de la importancia política de integrar a Brasil como miembro permanente del Consejo de Seguridad y su papel mediador y estabilizador respecto del «tercer mundo»y, en el marco de la economía política internacional, intentando salvar las negociaciones de la OMC, separándose de sus anteriores alianzas (Argentina, India, China) que mantenían posiciones más duras acerca de las exigencias hacia los países desarrollados; fortaleciendo el G20, por vía de un acercamiento a la «gobernabilidad global» de los grandes (Estados Unidos, UE, Japón); fortaleciendo el papel del FMI y desligándose de las anteriores posiciones críticas, por vía del pago de su deuda con el organismo y luego ayudando a su financiamiento para que este pudiera fortalecer su papel de prestamista y fiscalizador; tomando distancia del regionalismo «neoproteccionista» como el MERCOSUR y optando por uno nuevo: el «regionalismo brasileño», más flexible y pragmático (UNASUR)—además de un conjunto de estrategias nacionales que buscaban mejorar el posicionamiento internacional de la economía brasileña y de sus principales actores, privados y públicos.

En esta perspectiva, un papel clave lo constituyó la estrategia de internacionalización de las empresas de capital nacional, ayudando a los grandes gru- pos económicos, industriales y de servicios, y fortaleciendo el desarrollo de otros nuevos. Bajo las directrices de este modelo, la expansión hacia fuera de la economía brasileña —condición necesaria para alcanzar la interdependencia real en el mundo de la globalización, según el ideario «logístico»- opera de dos maneras: por la agregación de los emprendimientos nacionales a las cadenas productivas internacionales y por la inversión directa en el exterior, comenzando por la dirigida hacia los países vecinos (Cervo, 2008).

Para esta estrategia el gobierno de Lula realizó un estudio, creó un grupo de trabajo ad hoc y formuló una propuesta para la elaboración de políticas públicas $^{32}$. Asimismo, el gobierno de Lula da Silva impulsa la formación de megaempresas, con capacidad de competir en el mercado mundial. Mediante el financiamiento del Banco Nacional de Desarrollo Económico y Social (BNDES) y con un fondo de 58 mil millones de dólares, se promueve la formación de "colosos nacionales", mediante fusiones y adquisiciones en industrias como los alimentos, la celulosa, la telefonía y el etanol ${ }^{33}$, visión que se proyecta en las propuestas de la candidata del PT a las próximas elecciones presidenciales ${ }^{34}$.

32 Ver, Governo Federal, Termo de referência: Internacionalização de empresas brasileiras, Brasília (DF), diciembre de 2009.

33 «Brasil impulsa las megaempresas», en CLARín, Suplemento 1ECO Economía y Negocios, 17 de mayo de 2009; p. 21.

34 En definiciones sobre su eventual futuro gobierno, la candidata Dilma Rousseff señaló: «En Brasil (para nosotros), el Es- 
Raúl Bernal Meza • El pensamiento internacionalista...

\section{Conclusiones}

Al comenzar el siglo XXI existía una gran dispersión en torno a las ideas que intentaban dar una interpretación sobre las causas y consecuencias de la transición del orden mundial, con el fin de la guerra fría y de las doctrinas y teorías en que debían fundamentarse las políticas exteriores en un sistema mundial en rápido cambio.

Después de una etapa en que la política exterior brasileña pareció perder el rumbo, con contradicciones, cambios drásticos y abiertos enfrentamientos internos, que caracterizaría el período 1980-1992 (Hirst y Pinheiro, 1995); (Bernal-Meza, 2000) y de un lapso en que la coherencia de la política externa de F.H. Cardoso no significó la ausencia de profundos cuestionamientos por su visión neoidealista que la alejó de las tradiciones más autonómicas y tercermundistas, Lula da Silva recuperaría para el país la idea de un Brasil potencia, que la emparentó con aquella política exterior de los años 1974-1979: autonomía, búsqueda de poder, aspiración a competir por espacios de hegemonía regional, hemisférica y sistémica.

La llegada al gobierno del presidente Lula significó un cambio drástico respecto del período de Cardoso, en la concepción que los formuladores y tomadores de decisión tenían sobre la política mundial, no así respecto de los objetivos de inserción internacional del

tado es socio de los empresarios»; cfr. Diario Clarín, Buenos Aires, 26 de septiembre de 2009, p. 52. país. Cambiaron sustancialmente las visiones, las estrategias y las alianzas.

Lula da Silva implicaría la transición desde el neoidealismo del multilateralismo utópico de Cardoso al realismo clásico dominante en las relaciones internacionales (Cervo,2002; BernalMeza,2002). La política exterior brasileña reencontraba así, al inicio del siglo XXI, el pensamiento con que Rio Branco había sustentado la política exterior un siglo antes. Brasil se transformó en el único país sudamericano (y latinoamericano) en readoptar el realismo como teoría o paradigma de política exterior, desde que este fue abandonado, por el mismo Brasil, además de Argentina y Chile, entre mediados y fin de los años 1980. Leído bajo esta concepción, la delimitación de «esferas de influencia» resultaría un hecho absolutamente evidente de este aggiornamiento realista.

Bajo la recuperación de esta clásica concepción de la política mundial, la nueva política exterior brasileña concibió el sistema internacional como un juego de poder, de lucha entre los más poderosos actores del sistema. Ante el ascenso de la agenda de la «baja política» y la renovación metodológica y conceptual de la nueva diplomacia económica (Bayne \& Woolcock, 2007), el multilateralismo fue despojado de la utopía y se transformó en el juego de intereses, con ganancias y pérdidas a distribuir según el resultado de las negociaciones comerciales para lo cual resultaba fundamental recuperar la importancia de las coaliciones y alianzas entre países similares. 
Sin embargo, este no es un realismo puro sino que se combina con la visión grociana $^{35}$ del sistema internacional al respetar las normas y las instituciones del orden multilateral aunque impulsando simultáneamente un rediseño de las mismas en todas las agendas y buscando su propia participación activa en los mecanismos de la gobernanza global.

Retomando el pensamiento de Celso Lafer, el futuro de los escenarios globales se ajusta a la visión de un orden mundial en que se percibe una pérdida de la estabilidad hegemónica unilateral, que permite a Brasil un espacio de acción para su reposicionamiento como actor global, a partir del reconocimiento de su condición de potencia mundial emergente.

El instrumento clave de ese posicionamiento, a través de la reinserción internacional, sería la aplicación del modelo ideal del «Estado logístico».

De esta forma, Brasil ha combinado en los últimos años una activa participación en los foros multilaterales con la promoción de sus intereses nacionales desde una perspectiva realista. El elemento novedoso es que en la actualidad, paralelamente a la búsqueda de poder medido en términos de acumulación de capacidades militares, apunta a una estrategia fundamentada en un «multilateralismo de la reciprocidad»(Cervo y Bueno, 2008). Esta concepción deja entrever que Brasil

35 Gustavo Masera denomina esta conjunción de ideas «neogrocianismo ampliado"; cfr. MASERA (2010). ha ocupado progresivamente un lugar preponderante en los diversos dominios de las relaciones internacionales, desde la seguridad regional al plano de las finanzas.

La preocupación por poner el acento en Sudamérica como región diferenciada del resto del hemisferio, y particularmente de América Central y México, provino de la visión que la política exterior brasileña había adoptado hacia mediados de la década de 1990 y que se mantuvo latente hasta que fuera proyectada con fuerte dinamismo por la política exterior brasileña del gobierno de Lula da Silva (Bernal-Meza 2006; 2008; 2008a).La síntesis de esa visión ponía de manifiesto que, al sur del río Bravo (o río Grande) existían dos áreas bien definidas de influencia: una que comprende a México, el Caribe y América Central, percibida como dependiente económica y políticamente de los Estados Unidos y otra, Sudamérica, que comenzó a integrarse como región, más independiente y autónoma a partir de los proyectos de integración económica —el MERCOSUR y la CAN-y que, bajo el liderazgo del primero, estaría configurando un proyecto de cooperación política, la UNASUR, sostenida por un programa de integración en infraestructura, que sería la IIRSA ${ }^{36}$. Lula se ha preocupado permanentemente por asegurar el futuro de la UNASUR, una de las mayores apuestas de Brasilia en política exterior ${ }^{37}$.

\footnotetext{
36 Cfr. M. (2006) y O. (2006).

37 Según lo señaló <www.lanación.com>, el 29 de agosto.
} 
Raúl Bernal Meza • El pensamiento internacionalista...

Sin embargo, las reacciones negativas que tanto el gobierno brasileño como sus empresas internacionalizadas encontraron en la mayoría de los países sudamericanos debido a la aplicación en estos de políticas nacionalistas y reactivas contra el libre mercado vinculado a la apertura unilateral propia del período neoliberal anterior, llevarían al convencimiento de que el escenario sudamericano era ahora muy complejo para las estrategias políticas brasileñas frente a lo cual la diplomacia brasileña comenzaría el retorno hacia América Central, México y el Caribe.

Lula utilizó el multilateralismo internacional como instrumento para moderar el poder de la única superpotencia y también como camino para un reconocimiento global a los nuevos polos de poder emergentes, entre los cuales se encuentra Brasil.

La convergencia de intereses de la política exterior de Lula con áreas de países desarrollados, en particular la Unión Europea y algunos de sus principales miembros, les ha permitido, en conjunto, fortalecer el multilateralismo. Esta convergencia se ha sostenido en que ambos segmentos de este mundo global comparten la misma visión «multipolarista y multilateralista» que ha sido la base para la creación del G20 (en sustitución del viejo G7), el fortalecimiento de la estructura de las Naciones Unidas, el salvataje de las negociaciones multilaterales de comercio (Doha) y de la Cumbre de Copenhague sobre cambio climático (2009).
El pragmatismo de la política exterior realista de Lula ha llevado a la paradoja de que los países desarrollados hayan conferido a Lula el título de «estadista global» (en el Foro Económico Mundial, Davos, enero de 2010), mientras, simultáneamente, su país es la sede y ejerce el liderazgo del Foro Social Mundial, que representa justamente el ejemplo contestatario del orden económico mundial representado por Davos. Una contradicción que muchos sectores sociopolíticos sudamericanos no comprenden.

El instrumento para el nuevo destino e inserción global del Brasil es ahora el «Estado logístico». Este paradigma, en palabras de Amado Cervo, «no asiste pasivamente a las fuerzas del mercado y del poder hegemónico", sino que implica un conjunto integral de políticas públicas en los ámbitos científico-tecnológicos, industriales, comerciales, educativos, así como en el plano externo. Implica una coordinación del desarrollo interno y de la actuación internacional basada en una estrategia-país y en una amplia visión de los escenarios internacionales, y del rol de Brasil en ellos. Es así que Brasil busca su lugar en el escenario del siglo XXI a partir de su participación activa en el diseño y administración del orden mundial.

Sin embargo, los grandes objetivos globales del Brasil le presentarán enormes desafíos. Entre ellos, formar parte de los BRIC - el contrapoder que aspira a asumir parte del nuevo management internacional- como única potencia 
no nuclear del grupo. Al respecto, ya existen debates internos entre aquellos que consideran necesario mantener a un Brasil libre de armas nucleares y aquellos más cercanos a las posiciones duras del realismo, que piensan que no puede haber rango de potencia mundial sin desarrollo nuclear estratégico. De aceptarse esta última posición, Brasil debería no solo renunciar al Tratado de Tlatelolco, sino también a los Acuerdos «Compromiso» de Mendoza de 1991, de prohibición de armas químicas y bacteriológicas, firmados entre Brasil, Argentina y Chile, lo que daría, lógica y naturalmente, justificación a la Argentina para retomar la senda del desarrollo nuclear militar-estratégico. Una disputa que acabaría definitivamente con los proyectos de integración y cooperación sudamericana, que tienen como base la relación cordial y de entente entre Brasil y Argentina.

Brasil comienza a abandonar la posición unificada del MERCOSUR respecto de un acuerdo de libre comercio con la Unión Europea. Ese viejo propósito, firmado en Madrid en 1995, ya no forma parte de los intereses brasileños, porque sus formuladores de política consideran que ahora coartaría las posibilidades nacionales de inserción en la economía mundial y en los acuerdos regionales y multilaterales de comercio $^{38}$. Será por

8 Dice A. Cervo al respecto: «Al proyecto brasileño le repugna la integración hemisférica (ALCA), los tratados bilaterales de libre comercio e incluso el acuerdo Mercosur-Unión Europea para la creación de un área de libre comercio. En la óptica brasileña, todas estas posibilidades pene- tanto cuestión de tiempo que sus socios sudamericanos - y particularmente la Argentina- perciban que los intereses de su gran vecino ya no son coincidentes con los de ellos.

La última reflexión tiene que ver con la lectura desde la cual hemos abordado el texto. Obviamente, la visión ha sido Estado-céntrica, porque esa es la que los formuladores de decisión, sus élites y grupos de poder brasileños han impuesto predominantemente a las lógicas de la política exterior y la perspectiva con la cual observan la política mundial. Al incorporar la crítica sobre las debilidades que enfrenta en Brasil el esfuerzo por democratizar la formulación de la política exterior; donde la participación de otros actores sociales que puedan expresar sus intereses en dicha política es limitada justamente por la misma visión realista, ponemos también de relevancia que las desigualdades sociales internas condicionan a futuro las perspectivas y opciones del 'país por convertirse en líder regional y global, a pesar del enorme crecimiento económico y de su progreso en el camino de transformarse en una potencia mundial; con un aumento significativa de su relevancia e influencia internacional. Como señaló un especialista sobre este país, "aunque la economía brasileña es grande y vibrante, la distribución del ingreso en

tran a fondo en el ordenamiento interno y en la inserción internacional, de manera que comprometen la vocación industrial del país, bien supremo de la representación política y del interés nacional» (CERVO,2009a:85). 
Raúl Bernal Meza • El pensamiento internacionalista...

el país está entre las peores del mundo. Los frutos de esa gran economía no han sido distribuidos ni se han expandido hacia abajo /.../ Es difícil imaginar que un Estado-nación que fracasa en abordar las necesidades básicas de bienestar de su población pueda jugar un papel de liderazgo significativo en la escena mundial» (ROETT,2003:227).

En este sentido debe destacarse la decisión y voluntad de las administraciones del presidente Lula da Silva para poner a su país en el club de las potencias ascendentes del nuevo orden internacional, pero haciéndolo junto a considerables progresos en la erradicación de la pobreza y la extrema pobreza. La gestión Lula se propuso poner al Brasil en el contexto de las nuevas potencias mundiales en ascenso, mejorando también las condiciones de vida de la mitad más pobre de su sociedad.

\section{BiBLIOGRAFÍA}

Amorim, Celso (2007), A diplomacia multilateral do Brasil - um tributo a Rui Barbosa. Brasilia, FUNAG.

Arrigui, Giovanni (1994), The Long Twentieth Centuty, Londres, Verso.

(1996), o Longo SÉculo

XX. Rio de Janeiro, Contraponto Editora; São Paulo, Editora UNESP. (1998), A ilusão do desenvolvimento, Petrópolis, Editora Vozes, $4^{\mathrm{a}}$ ed.

Aymard, Maurice (1985), Nation-States and Interregional Disparities of Development, en Arrighi G. (ed.), Semiperipheral Development: The Politics of Souther Europe in the Twentieth Century, Beverly Hills, CA, Sage, 40-54.
Bayne, Nicholas y Stephen Woolcock, (ed.), The New Economic Diplomacy. DecisionMaking and Negotiation in International Economic Relations, Aldershot, Ashgate Publishing Limited.

Bernal-Meza, Raúl (1994), América Latina en la economía política mundial, Buenos Aires, Grupo Editor Latinoamericano. (1996), La globalización: ¿Un proceso y una ideología?. Realidad Económica, $\mathrm{N}^{\circ} 139$, p. 83-99.

(1997), La Mundialización. Orígenes y fundamentos de la Nueva Organización Capitalista Mundial, Realidad Económica, $\mathrm{N}^{\mathrm{o}} 150$, p. 33-52.

(1999), Las percepciones de la actual política exterior argentina sobre la política exterior del Brasil y las relaciones Estados Unidos-Brasil, Estudios Internacionales, Año XXXII, $\mathrm{N}^{\circ} 125$, eneroabril de 1999, pp. 51-82.

(2000), Sistema Mundial y MERCOSUR. Globalización, Regionalismo y Políticas Exteriores Comparadas, Buenos Aires, Universidad Nacional del Centro de la Provincia de Buenos Aires/Nuevohacer/ Grupo Editor Latinoamericano. (2002), A política exterior do Brasil: 1990-2002, Revista Brasileira de Política Internacional, Brasilia, IBRI, Año 45, No 1; pp. 36-71.

(2004), Multilateralismo y unilateralismo en la política mundial: América Latina ante el Orden Mundial en transición, Journal Historia Actual OnLine, Fall (5) 2004. [http://www.online. historia actual.com; http://www.hapress. com/haol.php?a=n05a11].

(2005), América Latina en el mundo. El pensamiento latinoamericano y la teoría de relaciones internacionales, Buenos Aires, Nuevohacer, 395 p.p.

$\left(2005^{\mathrm{a}}\right)$, Multilateralismo e unilateralismo na política mundial: América Latina frente à Orden Mundial em transiçâo, Revista Brasileira de Política Internacional, Año 48, $\mathrm{N}^{\circ}$ 1, 2005; pp. 5-23. (2008), La política exterior del Brasil: Claves para entender las dife- 
rencias con Argentina, en Revista Densidades, $\mathrm{N}^{\circ} 2$, octubre de 2008, pp. 25-42; ISSN 1851-832X (versión electrónica);

(2009), El Regionalismo.

Conceptos, paradigmas y procesos en el sistema mundial contemporáneo. Revista Aportes para la Integración Latinoamericana, Año XV, N 21/Diciembre 2009. $\left(2009^{\mathrm{a}}\right)$, Latin American

Concepts and Theories and Their Impacts in foreign Policies, en Sombra Saraiva José Flávio (ed.), Concepts, Histories and Theories of International Relations for the 21st Century. Regional and National Approaches, Brasilia IBRI, pp. 131-177.

Cervo, Amado Luiz (1994), Relações Internacionais do Brasil, en Amado Luiz Cervo (org.), O Desafío Internacional, Brasilia, UnB; pp. 9-58.

$\left(2000^{\mathrm{a}}\right)$, Sob o signo neoliberal: as relações internacionais da América Latina. Revista Brasileira de Política Internacional, Año 43, N² 2, pp. 5-27.

(2001), Relações Internacio-

nais da América Latina. Velhos e novos paradigmas, Brasilia, Instituto Brasileiro de Relaçôes Internacionais. (2002), Relações Internacionais do Brasil: a era Cardoso, Revista Brasileira de Política Internacional, Año 45, $\mathrm{N}^{\circ} 1$; pp. 5-35.

(2006) A Açao internacional do Brasil em um mundo em transformaçao, en Altemani de Oliveira Henrique y Antonio Carlos Lessa (Org.). : Relações Internacionais do Brasil. Temas e Agendas. Brasilia, FUNAG/Editora Saraiva, Vol.1, pp. 6-34.

(2008), Conceitos em Relações Internacionais. Revista Brasileira de Política Internacional, Vol. 51, $\mathrm{N}^{\mathrm{o}} 2$, p. 8-25.

$\left(2008^{a}\right)$, Inserção Internacional. Formação dos conceitos brasileiros, São Paulo, Editora Saraiva.

(2009), Concepts of International Relations, en Sombra Saraiva José Flávio (ed.). (2009a), La construcción del modelo industralista brasileño, en Revista DEP, Diplomacia, Estrategia y Política, Proyecto Raúl Prebisch, N ${ }^{\circ} 10$, octubrediciembre; pp. 74-86.

y Clodoaldo Bueno, (1992), (2002), História da Política Exterior do Brasil, São Paulo, Ática.

y Clodoaldo Bueno, (2008):

História da Política Exterior do Brasil, Brasília, Editora UnB; $3^{\text {a }}$ ed.

Cox, Robert (1981), Social Forces, States and World Orders: Beyond International Relations Theory, Millenium, 10:127-55.

Dupas, Gilberto (2005), Atores e poderes na nova ordem global, São Paulo, Unesp.

Escudé, Carlos (1992), Realismo Periférico. Fundamentos para la nueva política exterior argentina, Buenos Aires, Planeta.

(1995), El Realismo de los

Estados débiles. La política exterior del primer Gobierno Menem frente a la teoría de las relaciones internacionales, Buenos Aires, Grupo Editor Latinoamericano.

Ferrer, Aldo (1998), Hechos y ficciones de la globalización. Argentina y el MERCOSUR en el sistema internacional, México D.F., FCE.

Fukuyama, Francis (1992), El fin de la Historia y el último hombre. Barcelona, Planeta.

Gilpin, Robert (1981), War and Change in World Politics. Cambridge, Cambridge University Press.

(1990), La Economía Política de las Relaciones Internacionales, Buenos Aires, Grupo Editor Latinoamericano.

GrabendorfF, Wolf (2010), Brasil: de coloso regional a potencia global, Nueva Sociedad, No226, marzo-abril 2010.

Hirst, Mónica y Leticia Pinheiro, (1995), A política externa do Brasil em dois tempos, Revista Brasileira de Política Internacional, Año 38, $N^{\circ} 1$, pp. 5-23.

Новьвашм, Eric (2007), Historia del Siglo XX. Buenos Aires, Crítica, $10^{a}$ ed.

Huntington, Samuel (1993), The Clash of Civilizations? Foreign Affairs, vol. 72, no. 3, Summer, pp. 22-49. 
Raúl Bernal Meza • El pensamiento internacionalista...

(1996), The Clash of Civilizations and the Remaking of World Order, Nueva York: Simon \& Schuster.

Hurrell, Andrew (1992), Teoría de regimenes internacionales: una perspectiva europea. Foro Internacional, El Colegio de México, Vol. XXXIII, oct-dic., №5.

Keohane, Robert O. (1984), After Hegemony. Cooperation and Discord in the World Political Economy, Princeton University Press.

Keohane, Robert O. (1988), Después de la hegemonía. Cooperación y discordia en la política económica mundial. Buenos Aires, Grupo Editor latinoamericano.

KeOhane, Roberto O. y NYE, Joseph (1977), Power and Interdependence. World Politics in Transition, Little, Brown and Company (Inc.).

(1988), Poder e Interdependencia. La política mundial en transición, Buenos Aires, Grupo Editor Latinoamericano.

KraSner, Stephen, (1986), International Regimes. Ithaca, Cornell University Press.

LAFER, Celso (1996), "Brasil y el nuevo orden mundial", Archivos del Presente, Buenos Aires, Fundación Foro del Sur, Año 1, N 3, verano 95/96; pp. 61-80.

(2001), A identidade internacional do Brasil: pasado, presente e futuro; São Paulo, Perspectiva. (2002), La identidad internacional del Brasil, Buenos Aires, FCE.

Masera, Gustavo Alberto (2010), El Estado Logístico: el nuevo modelo de inserción internacional del Brasil ; trabajo presentado en el Seminario Internacional del Bicentenario; Tandil (Argentina), Universidad Nacional del Centro de la Provincia de Buenos Aires, 19 de mayo de 2010.

Mearsheimer, John J. (1994), The False Promise of Internacional Institutions. International Security, Vol. 19, No 3, winter 1994/95.

Moniz Bandeira, Luiz Alberto (1996), Política y relaciones internacionales en el MERCosur, Ciclos, Buenos Aires, Facultad de Ciencias Económicas, Universidad de
Buenos Aires, Año VI, Vol. VI, N ${ }^{\circ} 11,2^{\circ}$ sem; pp. 103-122.

(2009), Geopolítica e Po-

lítica Exterior. Estados Unidos, Brasil e América do Sul, Brasilia, Ministério das Relações Exteriores, Fundação Alexandre de Gusmão.

Nye, J. S. (2004), Soft Power: The Means to Success, en World Politics, Nueva York, Public Affairs.

Oliveira, Amâncio Jorge de y Alberto Pfeifer, (2006), O empresariado e a política exterior do Brasil, en Altemani Henrique y Antônio Carlos Lessa; volumen 2; pp. 389-427.

Pecequilo, Cristina S. (2008), A Política Externa do Brasil no Século XXI: Os eixos Combinados de Cooperação Horizontal e Vertical; Revista Brasileira de Política Internacional, Año 51, No 2, pp. 136-153.

Pinheiro GuimrÃes, Samuel (1999), Quinhentos anos de periferia. Porto Alegre-Rio de Janeiro, Editora da Universidade/UFRGS - Editora Contraponto.

Quintanar, Silvia (2009), Tendencias recientes en la integración y cooperación energética sudamericana. Perspectivas comparadas; Jornadas de Relaciones Internacionales 2009; FLACSO-Argentina, Buenos Aires, 1-3 de octubre.

RAPOPORT, Mario (1997), La globalización económica: ideologías, realidad, historia; Ciclos, Vol. VII, No 12 , pp. 3-40.

Roett, Riordan (2003), El papel de Brasil como potencia regional, en Paz Guadalupe y R. Roett (comps.), América Latina en un entorno global en proceso de cambio, Buenos Aires, ISEN/Muevohacer; pp. 227-246.

Rosecrance, Richard (1986), La expansión en el Estado comercial. Comercio y conquista en el mundo moderno. Madrid, Alianza Editorial.

Saraiva, Miriam Gomes (2007), As estratégias de cooperação Sul-Sul nos marcos da politica externa brasileira de 1993 a 2007, en Revista Brasileira de Política internacional, Año 50, $\mathrm{N}^{\circ}$ 2; pp. 42-59.

Schirm, Stefan A. (2007), Indicadores de liderança e modelos de análise para a nova 
política internacional do Brasil, en Costa Sérgio, Hartmut Sangmeister y Sonja Steckbauer (orgs.), O Brasil na América Latina. Interaçôes, Percepçôes, Interdendencias, São Paulo, Annablume/Fundaçâo Heinrich Böll; pp. 39-63.

Sennes, Ricardo U. (1999), "Brasil e os Fórum Multilaterais: o caso do GATT e do CS-ONU (1980-1995)"; Sâo Paulo, USP, paper.

Simonoff, Alejandro (comp.), (2010), La Argentina y el mundo frente al Bicentenario de la Revolución de Mayo; Buenos Aires, Editorial de la Universidad de La Plata.

Smouts, Marie-Claude (Dir.), (1998), Les nouvelles relations internationales. Pratiques et théories. Paris, Presses de la Fondation Nationale des Sciences Politiques.

Soares de Lima, María Regina (2005), A politica externa brasileira e os desafios da cooperação sul-sul; en Revista Brasileira de Política Internacional, Año 48; $\mathrm{N}^{\circ} 1$, 2005; pp. 29-41.

(2008), Liderazgo regional en América del Sur: ¿tiene Brasil un papel a jugar?, en Ricardo LAGOS (comp.), América Latina: ¿Integración o Fragmentación?, Buenos Aires, EDHASA; pp. 89-114.

Sombra Saraiva, José F., Amado Cervo, (org.) (2005): O Crescimento das Relaçoes Internacionais no Brasil, Brasilia, IBRI.

Souto Major, Luiz A.P. (2006), O Brasil e o regionalismo continental frente a uma ordem mundial em transição, en Revista Brasileira de Política Internacional; Año 49, No 2, 2006; pp. 42-59.

Vigevani, Tullo, et. al. (1999), Globalização e Segurança Internacional: a posição do Brasil. en Dupas Gilberto y Tullo Vigevani (org.), O Brasil e as Novas Dimensões da Segurança Internacional. São Paulo, Editora Alfa-Omega/FAPESP; p. 53-86.

Waltz, Kennet (1979), Theory of International Politics, Addison- Wesley Publishing Company, Inc.

(1988), Teoría de la Política Internacional, Buenos Aires, Grupo Editor Latinoamericano.
Wallerstein, Inmanuel (1974), The modern world-system. Capitalist agriculture and the origine of the european worldeconomy in the sixteenth century, Nueva York, Academic Press, Inc.

(1979), The Capitalist World-Economy; Nueva York: Cambridge University Press. 